\title{
Últimas palabras del médico charrúa Senaqué: novel hipótesis respecto a su interpretación
}

\author{
Last Words of the Charrúa Medicine-Man, Sennaqueh: \\ A New Hypothesis about their Interpretation
}

José Campione-Piccardo ${ }^{1}$

DOI: https://doi.org/10.26512/rbla.v10i2.20942

Recebido em abril de 2018

Aceito em maio de 2018

\section{Resumen}

En el presente artículo se sugiere una hipótesis alternativa respecto de la interpretación que se les ha dado a las últimas palabras del médico indígena charrúa Senaqué desde su fallecimiento en Paris el 26 de julio de 1833. La versión que iniciara el interno Camus, y que se ha mantenido hasta el presente, es entendible desde un punto de vista parisino y francés, pero no parece condecir con los orígenes de Senaqué, su carácter, su habla, su trayectoria y sus creencias, y es posible que se trate de una honesta pero errónea interpretación basada en la transcripción fonética al francés (mediante cambio de código lingüístico entre lo enunciado por quien habla y el decodificado por parte de quien le oye) por las personas de habla francesa que estaban presentes al momento de su muerte, y que fueran las únicas que le oyeron pronunciarlas.

Palabras claves: Charrúa. Guaraní. Últimos Charrúas. Senaqué. transcripción fonética oral. cambio de código lingüístico

\begin{abstract}
In the present submission a new hypothesis is suggested with respect to the interpretation that has been given to the last words of the Charrúa medicine-man Senaqué since his death in Paris on July 26, 1833. The version initiated by the intern Camus, which has lasted until now, is understandable from a Parisian or French point of view, but does not seem to echo Senaqué's origins, his character, his language, his trajectory and his beliefs, and it could possibly be the result of an honest but erroneous interpretation based on the phonetic transcription into French (i.e., code-switching between the word as uttered and the word as heard and decoded) by the French-speaking persons who were present at his death, and who were the only ones to hear him say them.
\end{abstract}

Keywords: Charrúa. Medicine-man. Sennaqueh

\footnotetext{
${ }^{1}$ Médico, científico y académico uruguayo-canadiense, retirado de la Agencia de Salud Pública del Canadá (PHAC/ASPC) y la Organización Panamericana de la Salud (OPS/ OMS). Ottawa, Ontario K1B 4T9, Canadá.
} 
Senaqué fue un médico indígena charrúa sobreviviente de la Matanza de Salsipuedes (Campaña 2004), el 11 de abril de 1831, con la que el General Fructuoso Rivera, primer presidente constitucional de la novel nación oriental, diera inicio a su campaña de limpieza de indígenas charrúas sublevados dentro del territorio. Un grupo de sobrevivientes a dicha emboscada fueron hechos prisioneros. Cuatro fueron llevados a Francia por François De Curel en 1832, siendo exhibidos en París como curiosidades antropológicas y sometidos a estudios por los frenólogos de la época (Rivet 1930). Uno de los cuatro charrúas era Vaimaca Pirú, un cacique charrúa que había contado con la confianza del General José Gervasio Artigas, y otro fue Senaqué, médico indígena o sepé $e^{2}$ su tribu e inseparable compañero. Senaqué fue herido de lanza en el tronco, y enfermo y desnutrido fue el primero en dejarse morir en Paris, el 26 de julio de 1833. Vaimaca Pirú le siguió poco después. Antes de morir, Senaqué fue llevado a la Maison Royale de Santé donde fue asistido por el interno Camus, quien dejara un sentido relato de las últimas horas del médico charrúa recogiendo las que, según su interpretación, fueron sus últimas palabras (Camus 1833). ${ }^{3}$ El 10 de agosto de 1833, bajo el título Pauvre sauvage!, el periódico Le Charivari (Chavari 1833) publica un artículo sobre la muerte de Senaqué en el que repite la versión de Camus. ${ }^{4}$ En 1840, M. César Famin, describe brevemente el periplo francés de los Charrúas poniendo en boca de Senaqué esas mismas palabras (Famin 1840). ${ }^{5}$ La misma anécdota la reproduce en 1844 Auguste Wahlen (Walen 1844), en 1858 la incluye X.-B. Saintine en su libro Seul! (Santine 1858), en 1863 la vuelve a citar Armand de Brossard (De Brossard 1863), y en 2017, Darío Arce Acenjo (Acenjo 2017), luego de ciento ochenta y cuatro años, vuelve a reproducir textualmente la versión originada por Camus.

Cuesta aceptar que las últimas palabras del sepé Senaqué hayan podido ser 'Oh Paris! Paris!'. En primer lugar, porque es muy poco probable que al morir haya evocado el nombre de una ciudad que conocía mal y en la que sufrió el escarnio de ser expuesto a los parisinos como una curiosidad de la naturaleza. En segundo lugar, resulta aún menos concebible que en el momento de morir pudiese haber enunciado un vocablo en un lenguaje que no conocía, ya que no hablaba francés y tenía un muy pobre conocimiento del castellano (Paul Rivet en su memoria titulada Les derniers charrúas (Rivet 1930) hace hincapié en el hecho de que «no había nunca querido adquirir las costumbres de los criollos ni aprender su lenguaje»). Sin entrar en el análisis de estas últimas palabras

\footnotetext{
${ }^{2}$ Médico o sabio indígena, en lengua charrúa (Sabat Pebet 1969).

${ }^{3}$ «Guardaba un silencio absoluto, el que él rompió solo una vez, sin provocación. $O h$ Paris! Paris! exclamó, y para quienes le escucharon en esa exclamación estaba toda su historia.»

4 «'Oh Paris! Paris!' son las últimas palabras que pronunció.»

${ }^{5}$ «Cercano a su último suspiro, este pobre hombre juntó todas sus fuerzas y gritó de un tono tan doloroso que todos los asistentes resultaron emocionados: ¡Paris! ¡Paris!».
} 
en tanto que discurso narrativo (Bakhtin 2012), es mucho más probable que Senaqué, quien durante su estancia en Paris «habla poco y contesta lenta y difícilmente» (Dumoutier 1833) ${ }^{6}$, en esas circunstancias, haya utilizado un vocablo de su lengua habitual, referido a algo o alguien evocativo de su vida pasada, de su propia cultura, cuya fonética pudiera haber creado un cambio de código lingüístico (Cantero 1995) (Cortés Moreno 2001) involuntario entre el término enunciado en un idioma y su inmediata decodificación en otro, resultando en un inconsciente calembour o juego de palabras entre dos lenguas, por la polisemia así se creada. Además, debe recordarse que en el lenguaje francés la palabra 'Paris' se pronuncia cercana a 'Parí' en castellano ('pa.si', en notación fonética (International Phonetic Association 1999)), con acentuación en la 'i' y sin sonido para la 's' de final de palabra. Ello puede haber inducido a error a las personas de habla francesa que presenciaron su muerte en el caso mucho más probable que él haya invocado un vocablo de su propia lengua con una fonética cercana a 'pa.si', aunque quizás más evocativo de su propia vida o creencias. La palabra 'Piri', posiblemente de origen guaraní, era utilizada por las diferentes tribus indígenas que poblaban las riberas del río Uruguay para designar las esteras de junco (Ruiz de Montoya 1639), los toldos así confeccionados y los campamentos que utilizaban dichas tolderías (Trelles 1870) ${ }^{7}$ (aunque a partir del siglo XVIII estos toldos ya se confeccionaban preferentemente con pieles y cueros de animales) (Rossi 2002). Es posible que, por extensión, este vocablo haya pasado a designar el hogar (Antón 1995), y probablemente también al poblado indígena (Antón 1998). La versión escrita de la palabra 'Pirí' reproduce (en portugués o castellano) su pronunciación aproximada, ya que no se sabe la pronunciación exacta que pudiera habérsele dado en el hablar charrúa de la época (García 2010), pero es probable que al ser enunciada por Senaqué, pudiera, en oídos parisinos, confundirse con la fonética de 'pa.ri'. Refuerza además la interpretación de que Senaqué haya enunciado una palabra indígena de uso corriente entre los Charrúas para designar su habitación y quizás a su pueblo, el que el frenólogo M. Dumoutier (Dumoutier 1833), en la cita que de él hace Paul Rivet en la memoria arriba citada (Rivet 1930), refiera haberle preguntado al cacique Vaimaca Pirú acerca de la muerte de Senaqué, a lo cual el cacique le contestó: «ha retornado al país, [...] él está volviendo.» ${ }^{8}$ Luego,

\footnotetext{
${ }^{6}$ «Desde su captura, es notorio que [Senaqué] es el menos comunicativo, sea por el efecto de su enfermedad o por la pena que experimenta, guarda sobre todos los hechos pasados un triste silencio y cuando mira a alguien, no es sino de costado y rápidamente. Desdeñoso, ve todo con un aire de desprecio, una especie de indiferencia con algo de apatía; como todos los de su raza se enorgullece de manifestar la más perfecta impasibilidad. Habla poco y contesta lenta y difícilmente.»

${ }^{7}$ «... empleada figuradamente, como especie de sinécdoque para significar las chozas de aquellos indígenas por el nombre de la planta que les servía de material para cubrirlas.» ${ }^{8}$ «Le he preguntado a Peru [sic] qué pensaba acerca de la muerte de su compañero: “Ah!,
} 
parece más probable que Senaqué en el momento de sentir que moría haya invocado sus orígenes, su gente y el lugar donde deseaba y esperaba retornar, y que ‘¡Pirí! Pirí!' (en guaraní-charrúa) y no 'Paris! Paris!' (en francés) hayan sido las últimas palabras que se ahogaron en su garganta el 26 de julio de 1833 .

Es difícil establecer la veracidad absoluta de cualquiera de estas versiones. Sin embargo, la novel interpretación que aquí se presenta parece plausible, tanto o más que la francesa, dado no solo los conocimientos lingüísticos de Senaqué, sino los aspectos históricos de su figura y su personalidad en tanto que indígena de la Banda Oriental y miembro de la nación charrúa. Además, contribuye a reforzar su memoria, al devolverle a sus últimas palabras un mayor poder evocativo y algo de la grandeza moral y espiritual con la que el sabio charrúa enfrentó todas las vicisitudes de su vida, incluida su propia muerte.

\section{Referencias bibliográficas}

Acenjo, D. A. 2017. La historia de los Charrúas llevados a Paris en 1833. http://www. enlacesuruguayos.com/Charruas.htm.

Antón, D. 1995. Piriguazú - el gran hogar de los pueblos del sur. Montevideo: Rosebud ediciones.

Antón, D. 1998. El pueblo jaguar: lucha y sobrevivencia de los charrúas a través del tiempo. Montevideo: Rosebud Ediciones.

Bakhtin, M. M. 2012. Problemas de la poética de Dostoievski. Vol. 3ra. edición. México: Fondo de Cultura Económica.

Campaña, M. 2004. "La guerra de los charrúas." Revista Guaragua, 141-164.

Camus. 1833. "Les derniers momens de Sénaque le charrua." Revue de Paris (H. Dumont) 5ème année (tome 5ème): 130-133.

Cantero, F. J., de Arriba, C. 1995. "El cambio de código: contextos, tipos y funciones." Actas del Congreso Nacional de AESLA. Valencia, España: Asociación Española de Lingüística Aplicada (AESLA). 278-290.

Chavari, Le. 1833. "Pauvre sauvage!" Le Chavari 2ème année (266).

Cortés Moreno, M. 2001. "Fenómenos originados por las lenguas en contacto: cambio de código, préstamo lingüístico, bilingüismo y diglosia." Wenzao Journal (Universidad Wenzao) 295-312.

De Brossard, A. 1863. Mes voyages avec le docteur Philips dans les républiques de La Plata. Tours, France: Mame et Cie.

Dumoutier, M. 1833. "Considérations phrénologiques sur les têtes de quatre Charruas." Journal de la Société Phrénologique de Paris Tome II: 74-102.

Famin, M. C. 1840. L'Univers ou Histoire et description de tous le peuples.... Paris, France: Firmin Didot Frères.

ha retornado al país", fue lo que me dijo, "él está volviendo.”» 
García, B. 2010. Palabras charruas conocidas y su significado. Setiembre 17. http://caio. uy.over-blog.com/article-palabras-charruas-conocidas-y-su-significado-57204447. $\mathrm{html}$.

International Phonetic Association. 1999. Handbook of the International Phonetic Association A Guide to the Use of the International Phonetic Alphabet . Cambridge, UK: Cambridge University Press.

Rivet, P. 1930. "Les derniers Charruas." Revista de la Socidad de Amigos de la Arqueología (El Siglo Ilustrado) IV.

Rossi, J. J. 2002. Los Charrúas. Buenos Aires: Editorial Galerna.

Ruiz de Montoya, A. 1639. Tesoro de la Lengua Guaraní. Madrid.

Sabat Pebet, J. C., Figueira, J. J. 1969. «Las lenguas indígenas del Uruguay.» Boletín histórico del Estado Mayor General del Ejército 188-220.

Santine, X.-B. 1858. Seul! Vol. 2ème ed. Hachette et Cie.,.

Trelles, M. R. 1870. "Informe de P. Policarpo Dufo sobre lo sucedido en la entrada que se hizo en el año 1715 al castigo de los infieles." Revista del Archivo General de Buenos Aires (Imprenta del Porvenir) Tomo II.

Walen, A. 1844. Usage et costumes de tous les peuples du monde. Bruxelles: Librairie Historique-Artistique. 